\title{
Kaiser Permanente National Total Joint Replacement Registry
}

\section{Aligning Operations With Information Technology}

\author{
Elizabeth W. Paxton MA, Maria C. S. Inacio MS, \\ Monti Khatod MD, Eric J. Yue MD, \\ Robert S. Namba MD
}

Published online: 20 July 2010

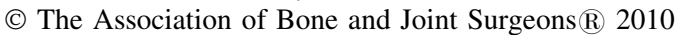

\begin{abstract}
Background A Total Joint Replacement Registry was developed in a large community-based practice to track implant utilization, monitor revisions and complications, identify patients during recalls and advisories, and provide feedback on clinical practices.

Questions/purposes We describe the development, implementation, and integration of this Total Joint Replacement Registry, highlighting critical steps in aligning information technology and operations.

Methods The primary Total Joint Replacement Registry data source consists of standardized electronic health record forms developed by consensus. The Total Joint Replacement Registry forms are integrated into the clinical workflow (preoperative, intraoperative, and postoperative)
\end{abstract}

Each author certifies that he or she has no commercial associations (eg, consultancies, stock ownership, equity interest, patent/licensing arrangements, etc) that might pose a conflict of interest in connection with the submitted article.

E. W. Paxton, M. C. S. Inacio ( $\square)$

Surgical Outcomes \& Analysis Unit of Clinical Analysis,

Kaiser Permanente, 3033 Bunker Hill Street, San Diego,

CA 92109, USA

e-mail: maria.cs.inacio@kp.org

M. Khatod

Department of Orthopaedics, Kaiser Permanente,

Baldwin Park, CA, USA

E. J. Yue

Department of Orthopaedics, Kaiser Permanente,

Sacramento, CA, USA

R. S. Namba

Department of Orthopaedics, Kaiser Permanente,

Orange County, CA, USA and produce a standardized progress note for electronic health record documentation. Secondary data are extracted from other electronic data sources using standard terminologies (ie, ICD-9 codes) to supplement the Total Joint Replacement Registry forms. Electronic screening algorithms are applied to identify complications, in combination with chart review validation and quality control mechanisms.

Results Three hundred fifty surgeons voluntarily contribute to the registry with $90 \%$ participation. The registry has been used for implant recalls and advisories, contract decision making, and identification of patients at risk for revisions (eg, younger patients having total knee arthroplasty). Tracking of overall survival of implants influenced clinical practice, with feedback resulting in the reduction of the number of unicompartmental and uncemented knee arthroplasties performed, usage of femoral head sizes $<28 \mathrm{~mm}$, and the number of minimally invasive surgical procedures performed.

Conclusions The Total Joint Replacement Registry has effectively aligned operations with information technology and leveraged that to enhance our ability to respond to recalls and advisories as well as improve quality of care, cost-effectiveness, and create research opportunities.

\section{Introduction}

Within the United States, more than 600,000 total joint arthroplasty (TJA) procedures are performed each year [11]. The volume and costs associated with these procedures are projected to increase dramatically over the next 20 years $[10,13]$. Despite the high volume and costs, there is limited evidence on the comparative effectiveness of 
different implant technologies and techniques in communitybased practice.

Although randomized controlled trials (RCTs) are the gold standard for assessment of clinical effectiveness, strict inclusion and exclusion criteria limit their generalizability. Clinical trials are often not practical when long-term followup is necessary, complication rates are low, and random assignment to treatment conditions is unethical. Patient registries provide an alternative to RCTs in these situations. Large registries also provide comparisons of implants and techniques in a real-world setting, allowing assessment of implant survival in patients with various comorbidities exposed to different clinical practice patterns [5]. The Swedish National Total Hip Replacement (THR) Registry has demonstrated the effectiveness of implant registries in influencing clinical practice and reducing revision rates [7, 15]. Specifically, the Swedish THR registry provided feedback on fixation techniques resulting in changes in clinical practice and reduced revision rates [15]. The demonstrated positive influence of the Scandinavian registries on clinical practice [11-13] has resulted in increased interest in the development of a national total joint replacement registry (TJRR) in the United States.

In 2001, our orthopaedic surgeons developed a TJRR to track and monitor TJA revisions, surgical site infections, venous thromboembolism events (VTE), and mortality within our healthcare system. The registry was developed to (1) notify surgeons during recall situations; (2) identify clinical best practices; (3) evaluate patient risk factors; (4) assess clinical effectiveness of implants; and (5) provide a foundation for research. The experience gained in developing this multicenter, national registry may assist others in the development of national orthopaedic registries.

In this article, we describe our experience in registry development and integration of the registry into our electronic health records (EHRs). We specifically review the development of the registry forms, database and staffing infrastructure; quality control methodology; registry oversight and governance, and critical steps for integration of registries with information technology (IT). We also highlight the patient safety, quality, contracting, and research benefits associated with integration of the alignment of operations with IT. Finally, we describe our future plans and directions.

\section{Registry Development}

Our integrated healthcare delivery system provides inpatient and outpatient care for more than 8 million people in eight different regions (ie, Southern California, Northern California, the Northwest, Hawaii, Colorado, Ohio, the Mid-Atlantic, and Georgia). Within our system,
350 surgeons provide total joint care and $80 \%$ of our surgeons are fellowship trained. Each year, our surgeons perform 17,000 TJAs at 43 medical centers.

In 2001, our orthopaedic surgeons initiated the TJRR in response to several implant recalls, changes in implant vendor contracts, and the need to monitor TJA outcomes. The development of the registry was supported by our regional and national orthopaedic chiefs groups who identified a team of orthopaedic surgeons to design and lead the registry. In addition to the core group of TJRR surgeon leads, a surgeon champion was identified at each center to facilitate development and implementation of the registry. Funding of the registry is through our integrated health plan. Initially, the TJRR was implemented under the research umbrella of the organization as an Internal Review Board approved research study. The specific aims of the study were: (1) document surgical techniques and implant characteristics; (2) characterize patients undergoing TJA and the relationships between these characteristics and techniques/implant selection; (3) compare incidence rates and variations in clinical care; (4) identify relationships between variations in practice and short-term outcomes; and (5) identify risk factors associated with TJA revisions.

To accomplish the project's specific aims, the registry leads benchmarked with existing TJA registries. In addition, a comprehensive literature review was conducted to identify key outcomes. The registry leads selected the core data elements based on the clinical questions of interest with each data element mapping to specific clinical questions. This core set of TJRR variables was modeled after the Swedish THR Register with revision as the primary end point and a focus on a minimal data set [15] to ensure reduced burden for participating surgeons.

The core data set was then shared with our surgeons for their input. Through consensus, our surgeons agreed to standardize their documentation by including the core data set in documentation of all TJAs. Initial challenges associated with establishing consensus on the core data elements consisted of balancing the need for minimal burden on the staff and surgeons while providing enough data to answer clinically relevant questions. As a compromise, we developed a modular approach with the core data elements as the registry foundation and the flexibility to supplement the core data set with patient reported outcome instruments for specific research projects.

The TJRR therefore consists of standardized forms integrated into the clinical workflow at the point of care: a clinic preoperative form, an operative form completed during the procedure, and a postoperative form completed at all TJA followup visits [20]. These standardized forms were piloted at limited centers to identify reliable data elements and determine methods for integration into the workflow. For example, a discharge form with information 
regarding complications during the hospital stay was eliminated due to the challenge of integrating the form into the hospital discharge process. Other TJRR forms were modified using surgeon and staff input, response rates, redundancy, and degree of missing values. Any variables that required detailed definitions were also eliminated during this pilot phase. The pilot forms contained all essential variables (Table 1) plus additional ones that were later eliminated from the initial forms due to a high percentage of missing values, inconsistencies, and

Table 1. TJRR data fields and data sources

\begin{tabular}{|c|c|c|}
\hline Data & Variables & Data Source \\
\hline \multirow[t]{10}{*}{ Patient } & Patient medical record number & TJRR form, EHR \\
\hline & Patient name & TJRR form, EHR \\
\hline & Age (DOB) & TJRR form, EHR \\
\hline & Gender & TJRR form, EHR \\
\hline & ASA score & TJRR form, EHR \\
\hline & Comorbidities & TJRR form, EHR \\
\hline & BMI & EHR \\
\hline & Race & EHR, Other \\
\hline & Diagnoses & TJRR form, EHR \\
\hline & Prior surgeries & TJRR form, EHR \\
\hline \multirow[t]{8}{*}{ Procedure } & Procedure & TJRR form, EHR \\
\hline & Procedure date & TJRR form, EHR \\
\hline & Laterality & TJRR form \\
\hline & Surgeon (blinded code) & TJRR form, EHR \\
\hline & Surgical approach & TJRR form \\
\hline & Anesthesia & TJRR form, EHR \\
\hline & DVT prophylaxis & TJRR form \\
\hline & Infection prophylaxis & TJRR form \\
\hline \multirow{3}{*}{$\begin{array}{l}\text { Hospital } \\
\text { Admission }\end{array}$} & Hospital & TJRR form, EHR \\
\hline & Discharge disposition & EHR \\
\hline & $\begin{array}{l}\text { LOS (admission/discharge } \\
\text { dates) }\end{array}$ & EHR \\
\hline \multirow[t]{2}{*}{ Implant } & Fixation & TJRR form \\
\hline & $\begin{array}{l}\text { Implant characteristics } \\
\text { (manufacturer, catalog } \\
\text { and lot numbers) }\end{array}$ & TJRR form \\
\hline \multirow[t]{10}{*}{ Outcomes } & Intraoperative complications & TJRR form, EHR \\
\hline & Postoperative complications & TJRR form, EHR \\
\hline & Hospital readmissions & EHR \\
\hline & Revisions & TJRR form, EHR \\
\hline & Re-operations & TJRR form, EHR \\
\hline & Death & EHR, Other \\
\hline & Radiographic assessment & TJRR form \\
\hline & Health plan membership & EHR, Other \\
\hline & Patient satisfaction (VAS) & TJRR form \\
\hline & Pain (VAS) & TJRR form \\
\hline
\end{tabular}

TJRR = Total Joint Replacement Registry; EHR = Electronic Health Record; ASA = American Society of Anesthesiologists; VAS = Visual Analog Scale. questions related to definitions (eg, occupation). The final forms contained patient (eg, age, gender and diagnoses), procedure (eg, operative date, laterality, surgical approach), hospital admission (eg, length of stay, discharge disposition), implant and fixation information (eg, manufacturer, catalog and lot numbers) and outcome variables including complications (ie, surgical site infections, VTE), revisions, re-operations, hospital readmissions, and death.

After several months and feedback from the frontline staff and surgeons, the TJRR forms with a core data set, high participation (90\%), completion (implant completion in primary THA $98.4 \%$, implant completion in primary TKA $96.7 \%)$, and accuracy rate $(98.8 \%)$ were finalized (Appendix 1). On an annual basis, surgeon leads ask for input from participating TJRR surgeons to add new procedures and modify the forms based on changes in practice (eg, addition of Birmingham hip resurfacings and minimally invasive surgeries).

\section{Leveraging Existing Electronic Data Sources}

In addition to the standardized TJRR forms, EHR database tables, claims databases, and health plan membership databases are used for validation, to identify patients lost to followup, and to supplement the TJRR forms with additional data elements.

HealthConnect $^{\mathrm{TM}}$ is the EHR implemented throughout our organization in 2006. This system is a customized product primarily managed by Epic Systems Corp (Verona, WI) but includes applications from several other vendors as well. This EHR includes clinical applications (such as ambulatory, inpatient, emergency room, operating room, etc), access applications (admission, discharge, registration, scheduling), revenue, billing and claims optimization, member and affiliated applications, financials, data integration (reporting, data repository, healthcare data management), and several other applications (bar code scanning, mobile computing, etc). The information collected from HealthConnect ${ }^{\mathrm{TM}}$ is stored permanently into a Clarity $^{\mathrm{TM}}$ database (GridApp Systems, Inc, New York, NY). This relational database is updated nightly and is organized into multiple tables, broken down by modules of the applications mentioned above. All the information is linked by specific encounter identifiers, transaction identifiers, and patient identifiers. This database allows, through secure connections, the extraction of the aggregate data using various database extraction tools, such as SQL (Structured

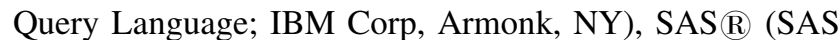
Institute Inc, Cary, NC), or Crystal Report (SAP America, Inc, Newtown Square, PA). We have established extraction routines using both SAS $®$ and SQL depending on the efficiency of the connections to certain tables. 
International Classification of Diseases, 9th Revision, Clinical Modification (ICD-9-CM) procedure codes are used to identify all TJAs using our EHR database. Claims databases identify additional TJAs at contract facilities using the same codes. This provides the independent data sources for validation of TJRR participation. Additional ICD-9-CM procedure and diagnosis codes, American Society of Anesthesiologists (ASA) scores [2], operative time, patient birth date and gender, hospital readmissions, and outpatient encounters are also extracted from our EHR

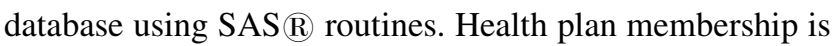
extracted from the Membership Information Database on all TJAs, providing information regarding patients who have left the health plan and are lost to followup. Mortality is extracted from our Membership Information Database that links to state death records and to our EHR database to capture inhouse mortality. Both health plan membership and mortality are used in censoring TJRR data. Finally, this information from the multiple existing data sources (EHR, Membership Information Database, and Claims) is linked to the registry patients and procedures via the unique identifier for the patient (ie, medical record number) and the operation (operative laterality and operative date) (Fig. 1). TJRR data from the EHR Clarity ${ }^{\mathrm{TM}}$ databases and other electronic data sources are extracted using SAS $\AA$ and merged into a

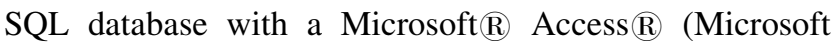
Corp, Redmond, WA) front end. Usage of these databases reduces the burden on frontline staff and surgeons.

\section{Registry EHR Integration}

Leveraging existing data sources provided the registry with enormous power to increase its data quality and validation. The next step in the development of our registry was to establish functional interoperability with our EHR. To accomplish this, tools needed to be developed to transition our paper-based forms into the EHR to collect the registryspecific information, provide patient level information and clinical documentation, and allow extraction of data to merge with our historical database.

Smartforms are the electronic, standardized EHR forms developed for clinic preoperative and postoperative TJRR documentation (Appendix 2). Smartforms allow direct data entry into EHR as discreet, extractable fields and automatic generation of a standardized progress note for documentation. In developing these forms over a 5-year period, we identified several critical steps for EHR integration. First, forms must be standardized with discreet data fields and allow easy access and use by the provider. Second, the tool must provide a benefit to the frontline user beyond registry data capture, such as producing a progress note for documentation. Third, dissemination of the tools and training must be approached systematically. Training must be customized for different levels of providers. Multiple training techniques, such as face-to-face training, e-mail tutorials, frequently asked questions, trainer manuals, and champion educators, must be used. Linkage of data is also

\section{TJRR Inputs}

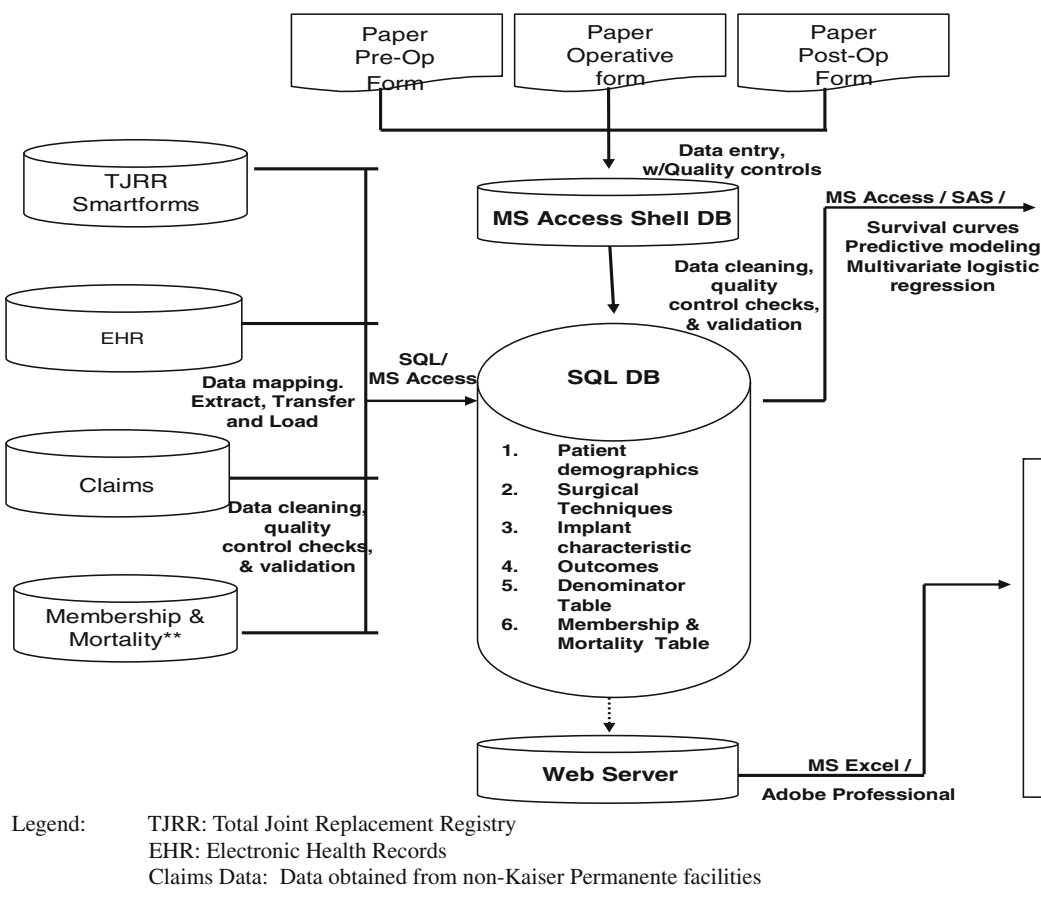

TJRR Outputs

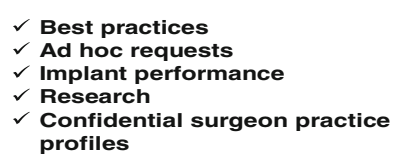

Global navigation \& static pages

- Annual report

Quarterly participation reports Conference presentations \& posters Journal publications

Dynamic web-based reports

$\checkmark$ Trends reports

$\checkmark$ TJR risk calculator

Fig. 1 A diagram illustrates the TJRR database. 
critical. EHR registry tools must have the ability to link different sections of the data completed by different providers. Correct linkage of multiple joints evaluated during the same visit is also important. The ability to edit information once the encounter has been closed is also crucial. These programming and linkage issues highlight the need for mandatory unique identifiers between data sources (to identify patient, laterality, and joint) and linkage within the medical records (to decrease number of places the same information was entered). Finally, quarterly reports to the surgeons, clinic and OR staff on usage, missing values and errors are necessary. Incorporation of the usage for all patient visits must be consistently reinforced. This feedback must be provided at regular time intervals and provide specific recommendations customized to each provider.

\section{Bar Code Scanning}

Bar code scanning of implants has also produced key learnings regarding alignment of IT and operations. Initial attempts at bar code scanning implant catalog and lot numbers into a Web-based data system outside our EHR were not successful due to the need for dual documentation. More recent attempts in bar code scanning directly with our EHR operative module have produced some challenges, such as technical problems with the scanners, inability to scan items not in our supply file, nonrecognizable bar code languages, preference of the operating room staff in keyboard data entry, and the complexity of maintaining lookup tables for the implants. As we overcome these challenges, extraction of these data directly from our EHR will be the next major improvement in the work reduction burden while creating a transparent extraction protocol of the registry's most critical data elements.

\section{TJRR Quality Control and Validation}

Data integrity and quality control are critical features of the TJRR database. The TJRR SQL database with front-end

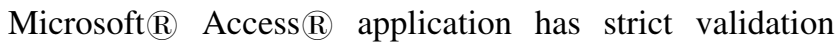
rules limiting data entry to predetermined characters, dates, and integers. In addition to the predefined validation rules, quality control queries are constantly applied to the data to identify out of range values, duplicate entries, missing information, and inconsistent values. These cases are followed up with chart review to ensure the highest level of data integrity.

Another important feature of the TJRR is the validation of cases to ensure capture of all TJAs. On a quarterly basis, EHR and claims databases are used to confirm the cases registered in the TJRR. Based on this information, quarterly participation reports are sent to department chiefs, administrators, and the surgeon champion. Surgeon champions serve as advocates for the registry at each participating center. The champion is responsible for communicating registry participation and findings to their locations and maintaining contact with the registry staff to solve any logistic issues in the data collection process. Using this process, centers can complete missing forms retroactively to increase their registry participation rates. While most TJRR data are collected prospectively, an additional 3\% are captured using this retrospective method.

Outcome validation is yet another important aspect of the TJRR. The TJRR uses a comprehensive validation program that consists of electronic screening of adverse events, chart review validation, and the use of guidelines for standardized definitions. The registry forms in combination with our EHR using ICD-9-CM codes serve as a mechanism for adverse event detection. All identified deep vein thrombosis, pulmonary embolism, surgical site infections, and revisions are confirmed using chart review adhering to the Center for Disease Control and Prevention (CDC) guidelines [16], Agency for Healthcare Research and Quality (AHRQ) Patient Safety Indicators [1] guidelines, and surgeons' predetermined clinical guidelines for confirmation of complication and revisions. The CDC guidelines are used to determine whether an infection was present and whether it was deep or superficial. The guidelines provide instructions on how long to screen patient activity, as well as symptoms and cultures associated with each type of infection. The AHRQ Patient Safety Indicators are ICD-9 diagnostic code algorithms that assist in the screening of the patients' charts for venous thromboembolic events. Finally, we use the surgeons' determination of revisions in the registry as any postoperative procedure in the same joint that required a component exchange. This data screening for complications and chart review component is a critical feature of the TJRR, ensuring standardized nomenclature and accuracy.

\section{Staffing and Oversight}

The TJRR staffing has evolved over the years with the growth and expansion of the registry program. Registry staff consists of four different skill sets: (1) data entry specialists for data entry and quality control checks; (2) SQL and SAS $\mathbb{R}$ programmers for data extraction, manipulation, merging, and database maintenance; (3) biostatisticians to conduct and interpret statistical analyses; and (4) clinical project managers to provide registry in-services and conduct chart reviews for validation of cases and complications. The implant registry staff 
supports five orthopaedic (TJRR, Anterior Cruciate Ligament Reconstruction, Spine, Hip Fracture, and Shoulder Replacement) and three cardiac (Implantable CardioverterDefribillators, Pacemakers, Valve Replacement) registries and reports to our organization's national quality structure.

Surgeon leads from each of the eight participating regions provide the clinical content guidance of the TJRR. These surgeons are involved in all aspects of registry operations and oversight, such as maintaining participation, form modifications, and response to data requests. In addition, a steering group, the Interregional Implant Registry Committee (IIRC), provides oversight and guidance of registry operations. The IIRC consists of surgeons, quality representatives, and researchers from the participating regions. This oversight group reports to our organization's national quality committee. A scientific committee was also established with orthopaedic surgeons, researchers, and biostatisticians from the different regions to prioritize research requests and assist investigators. This committee reports to the IIRC oversight group.

\section{Key to Success in Registry Development}

In developing the TJRR and expanding this model to other specialty registries, we have learned several keys to success (Fig. 2). First, we found benchmarking with existing registries (Swedish THR Registry $[8,14,15]$ and Norwegian Register [6]) was important in the development phase. Benchmarking provided guidance on selecting key data elements, clarifying and determining data definitions, and learning about successful methods for incorporation of registry data collection into the clinical work flow. Second, registries initiated, owned, and maintained by the participating physicians have a higher likelihood of success. Our surgeons are actively involved in every aspect of the TJRR, including development, maintenance, expansion, reporting, and oversight. Third, minimal burden and integration into the workflow are critical for registry success. Whenever possible, processes must be replaced instead of added into the workflow for successful adoption of registry data capture. Leveraging existing administrative databases is important for reducing data collection burden on frontline staff. Fourth, registries need rigorous validation and quality control mechanisms to ensure accuracy and reliability. Strict guidelines and definitions must be applied for consistent capture. Finally, ongoing feedback to the participating surgeons and staff is critical for registry participation and success. Feedback using a variety of communication mechanisms is necessary to increase participation, ownership, and application of registry findings within clinical practice.

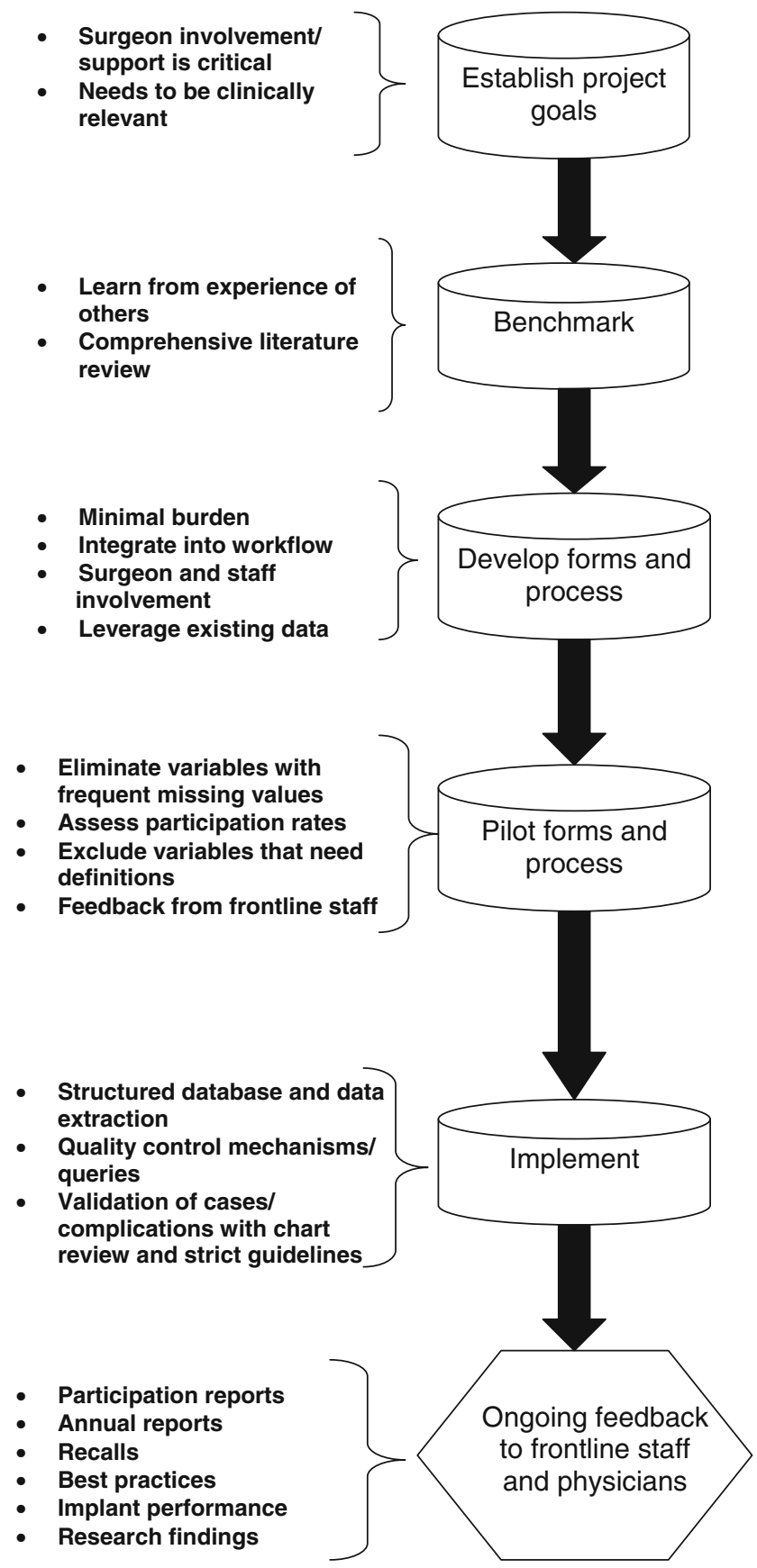

Fig. 2 A flowchart illustrates TJRR development.

\section{Current Status and Uses}

Currently, 350 surgeons from 43 medical centers contribute to the TJRR. Of our eight regions, the six regions in which we own our own hospitals contribute to the registry. The TJRR contains over 100,000 joints and has $90 \%$ voluntary participation. Incentives for participation include the potential to participate in research studies, confidential clinical practice profiles, and the use of the registry in advisories and recalls. This participation is nondifferential 
among participating medical centers and surgeons and is closely followed by the registry. When forms are not provided to the registry, we continue to track the TJAs using EHR data to capture revision and surgical site infection information. This is a smaller and limited data set but used by the registry to monitor outcomes of all TJAs and monitor any selection bias influence.

In addition to the TJRR, we have implemented four additional orthopaedic registries including an Anterior Cruciate Ligament Reconstruction Registry (9,900 cases, 208 participating surgeons from 34 centers), a Shoulder Replacement Registry (2,650 cases, 209 surgeons from 29 centers), a Hip Fracture Registry (20,277 cases, over 1813 surgeons from 27 centers), and a Spine Registry (2,500 cases with 50 participating surgeons from 6 centers). Beyond orthopaedics, we have also implemented a Heart Valve Replacement Registry (15,000 implants, 5 centers and 5 surgeons), Implantable Cardioverter-Defribillator Registry (14,000 implants, 6 centers with 30 participating physicians) and a Pacemaker Registry (30,000 implants from 33 centers and 230 participating physicians).

\section{Patient Safety and Quality of Care}

Although initially a research project, the TJRR transitioned from research to the quality umbrella in 2006 to focus on patient safety and quality improvement efforts. The TJRR has since positively influenced patient safety and quality of care in our organization in several ways. Most importantly, we can immediately identify and produce a list of patients with recalled implants. In addition, we can track revision rates, surgical site infections, and other possible adverse events related to the recall. The registries are also used to investigate early warning signs of potential device failures identified by physicians, companies, the Food and Drug Administration before formal recall announcements. The registry department works closely with our national recall department to respond to signals, recalls, and advisories for early identification of device failures. Some examples of recalls and advisories where our protocol has been used include the DePuy LCS $\mathbb{R}$ knee implants in 2005, Stryker/Howmedica Trident $\mathbb{R}$ hip

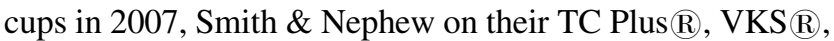
and RT Plus (R) knees in 2007, and Zimmer Durom (B) hip cups in 2008. This approach has also been applied to other voluntary recalls, such as the Articular Surface Replacement (R. by DePuy, where we identified approximately 600 patients in our registry and are now monitoring for any subsequent complications. Overall in 2009, our registries were used to investigate 15 recalls, advisories, and concerns associated with specific implant devices.

The TJRR also provides a mechanism for tracking and monitoring TJA revisions and complications. For example, we now know our revision rates and reasons for revisions and can track and monitor across time. Cumulative survival rates of our primary THAs and TKAs at 5 years are $97.3 \%$ $(\mathrm{n}=21,548)$ and $97.3 \%(\mathrm{n}=39,286)$, respectively. The leading causes for revision within 5 years in the primary THAs are instability (44\%) and infection (20\%), and for TKAs infections (41\%) and instability (19\%). We monitor all revisions and complications related to the procedures quarterly. We provide this information to all locations yearly or by request at any time throughout the year. Multivariate statistical analyses are conducted at least once a year on the entire registry population to determine patient risk factors associated with revisions and surgical site infections. This information is also disseminated in an annual report to our surgeons.

In addition to tracking revisions, the TJRR is also used for surgical site infections surveillance within our organization. Electronic screening mechanisms and chart review are used to identify all TJR postoperative infections. These data are used by our infection control specialists for reporting, monitoring of surgical site infection rates, and implementation of quality improvement efforts.

The TJRR also improves quality of care by identifying patient risk factors associated with complications and revisions. Using the TJRR, patient risk factors associated with revision, infection, pulmonary embolism, and deep vein thrombosis have been identified [9, 17]. Identification of patients at higher risk for revisions (ie, younger patients, patients with diabetes, patient with higher ASA scores), surgical site infections (ie, higher body mass index, patients with diabetes), and thrombotic events (ASA scores, prophylactic medication, anesthesia type) provides an opportunity for perioperative counseling to enhance quality of care.

Finally, the TJRR is critical for identification of clinical best practices. Revision and complication rates can be tracked and benchmarked across medical centers and regions to identify surgical techniques and implant characteristics associated with higher survival rates and lower rates of complications. Risk-adjusted medical center revision rates are provided to identify centers with higher revision rates. These findings are shared using dynamic feedback loops including newsletters, e-mails, confidential surgeon practice profiles, dynamic Web-based reporting, national and regional physician and staff meetings, presentations at medical centers, and national conferences to communicate with frontline staff and surgeons. Feedback from the registry along with literature reviews indicating higher revision rates in unicompartmental knees, uncemented total knee fixation, femoral head sizes of less than $28 \mathrm{~mm}$, and minimally invasive surgical procedures has resulted in a reduction in these techniques and devices [20]. 


\section{Cost-Effectiveness}

The TJRR has also provided an important role in costeffectiveness by allowing us to determine the best implants for our patients. For example, the registry allows us to evaluate marketing claims associated with more expensive technology and/or new technology. Device utilization and performance data from the TJRR are used to make informed decisions about implant contracts and purchasing decisions. By optimizing clinical practice and thereby reducing rates of revision surgery, the TJRR will further result in cost savings.

The TJRR has also been used to develop a mechanism for patient-centered followup care. Using the TJRR, this program automatically generates a list of patients due for a followup visit and e-mails the list to providers to schedule phone or e-mail visits. This program is currently being expanded to automatically generate e-mails sent directly to patients using secure messaging, ordering radiographs, and asking patient to respond to Web-based questionnaires. This followup process has the potential to save millions of dollars in office visits.

\section{Research}

In addition to quality and cost-effectiveness, the TJRR also provides a foundation for research activities. Initial publications have focused on early failures and complications [3, 9, 17-19]. The TJRR has been used for epidemiologic reviews of procedure volumes [10], trends, and projections of volumes. We linked our data to the other administrative databases available at our institution to evaluate utilization of our members after discharge [3] and study utilization rates after the procedures. Additional areas of focus include assessing the impact of antibioticloaded cement in TKAs [17] on postoperative infections and survival of TKAs in patients with cemented knees and noncemented knees. These are all examples of hypothesisdriven questions that registry data can be used to answer and contribute to the orthopaedic community. As the TJRR matures with longer-term followup, additional publications are anticipated.

\section{Discussion}

The demand for TJAs in the United States is projected to increase by $174 \%$ for primary hips and $673 \%$ for knees by the year 2030 [11]. In addition to increases in TJA demand, annual TJA hospital charges are projected to increase more than $300 \%$ by 2015 [11]. Despite the high volume and cost, a national system does not exist to compare the survival of devices and surgical techniques. Patient registries provide an opportunity to track implant utilization and trends and to assess longitudinal implant performance. Our purpose was to share critical steps for successful development and integration of a TJRR into an EHR.

The TJRR has both strengths and limitations. The TJRR's large volume with contemporary implants in community-based practice provides revision and complication data representative of community-based practice. Our integrated system allows us to capture data at every encounter in all settings of care, providing a unique opportunity to assess longitudinal revision and reoperation rates. The degree of surgeon support and involvement in the registry is also a strength of the TJRR. Surgeons are involved in all aspects of the registry development, maintenance, and oversight, providing clinical expertise and direction. Organizational support is also a strength of the TJRR structure with funding from our health plan and oversight from our IIRC steering committee. In addition, the integration of data capture at the point of care is novel with alignment of operations and IT. This innovative method for standardized EHR documentation with electronic screening algorithms to detect adverse events and the comprehensive validation and quality control of the TJRR provide a model for other registries.

Although the TJRR has several strengths, it also has limitations. First, full interoperability with our EHR has not yet been achieved. While data are extracted from the EHR into the registry SQL database, the TJRR does not yet link back to the EHR to provide a clinical decision tool at the point of care. Efforts are underway to integrate risk calculators and real-time TJRR summary statistics into our EHR for clinical decision-making tools. Second, only clinic forms are completely integrated into our EHR while operative forms and implant information remain paper based. As we overcome the challenges of bar code scanning and adopt scanning nationally with our organization, we plan to transition to a completely electronic system. Another limitation of the TJRR is the $90 \%$ participation rate. While a high participation rate, especially considering the voluntary nature for 350 participating surgeons, this raises the question of selection bias in registry participants. Fortunately, we are able to capture patient demographics, complications, and revisions from our EHR despite the missing TJRR forms. Demographics and revision rates in those who have forms versus those with only secondary data are nondifferential, suggesting participation is not systematically biased. Finally, the registry is focused on a core data with revision as the primary end point. Clinical outcomes are limited to visual analog scales for pain and satisfaction. However, with the implementation of virtual visits, plans for patient-reported outcomes on cohorts of patients for research purposes are underway. As is the case 
with all registry studies, loss to followup and missing data are limitations that need to be addressed. Within our registry, we have addressed these limitations using statistical methods, such as sensitivity analyses, multivariate analyses, propensity scores, and multiple data imputation. Considering these limitations, registry results must be assessed in conjunction with RCTs and other prospective studies in clinical decision making.

In developing a TJRR registry, we have identified several critical features to achieve success. First, surgeons must be involved in all aspects of the registry operations and oversight. Second, minimal burden to the physicians is important to maximize voluntarily participation. Third, optimizing the use of existing databases can reduce the demand on frontline staff. Fourth, electronic screening of complications requires validation of the cases according to standardized definitions. Finally, demonstrating the value of the registry and providing ongoing feedback to the participating surgeons and staff are critical for registry participation and success.

In aligning operations and IT, we have gained experience in registry EHR integration. Several iterations of EHR data capture have been attempted based on successes and failures. Some important observations include the need for integration into the workflow, incentives for participation such as progress note generation, customized training on data entry, continuous feedback to the frontline staff, and the need to link episodes and encounters and linkages for multiple joints. Future EHRs should include registry modules that are incorporated in the workflow, easily modifiable, and bidirectional with discreet data elements.

Despite the challenge of integration of the TJRR into our EHR, the TJRR has enhanced patient safety, quality, contracting, and research. Patient safety has been influenced by the registry's ability to identify problems associated with devices before official announcement of recalls. For example, patients with problems associated with a THA cup recalled in 2008 were identified before the recall of the device and implants were taken off the shelf immediately. The TJRR has been instrumental in investigating more than 15 recalls, advisories, and concerns with implants in 2009 alone. Risk factors associated with revisions and complications have also been identified. Similar to the experience in other registries [4, 8, 15], quality of care has been enhanced with timely feedback to physicians on implants and techniques associated with higher rates of revisions and complications. This feedback in combination with prospective studies indicating higher revision rates in unicompartmental knees, the uncemented TKA technique, and smaller femoral head sizes has resulted in a reduction in these implant choices and techniques. Contracting within our system has also benefited with the ability to investigate claims of new technology and ability to compare implant survival to identify the best implants for our patients.

As the TJRR grows and develops, we face new challenges and must be able to adapt for future success. Ongoing focus on participation is a key component of the registry, as is strategic management of multiple data requests as our data mature and offer the opportunity to answer important clinical questions. Future areas of focus for our TJRR currently underway include (1) interactive risk calculators; (2) automated postmarket surveillance with bidirectional EHR registry data exchange; (3) bar code scanning of implants; (4) complete integration and transparency with our EHR; and (5) interactive patient Web site with patient-centered outcomes collection capabilities.

Collaboration with other national initiatives is also a key future direction. In assessing the positive impact of the registry within our system, we recognize the vast potential for a national US TJRR. For a US TJRR to be successful, cooperation among implant manufacturers, healthcare insurance providers, government, patient advocacy groups, and surgeons is necessary. Surgeons will need to take the lead, driving the development, implementation, and reporting of a national effort. The effort will also need to focus on minimal burden and continuous feedback to provide incentives for participation. Early demonstration of the impact on quality and research will be necessary to sustain interest and participation in a national effort. Existing TJRRs such as those in Sweden and Norway and US registries such as the American College of CardiologyNational Cardiovascular Data Registry and the Society of Thoracic Surgeons national database provide models for a national TJRR. Benchmarking with existing orthopaedic registries and national registries in other specialties can help pave the way for a national TJRR to improve postmarket surveillance of implants and improve quality of care through identification of clinical best practices.

Acknowledgments We thank all of our orthopaedic surgeons and the registry staff who contribute to the success of the TJRR. 
Appendix 1. Total Joint Replacement Registry forms (hip and knee operative, preoperative, postoperative)

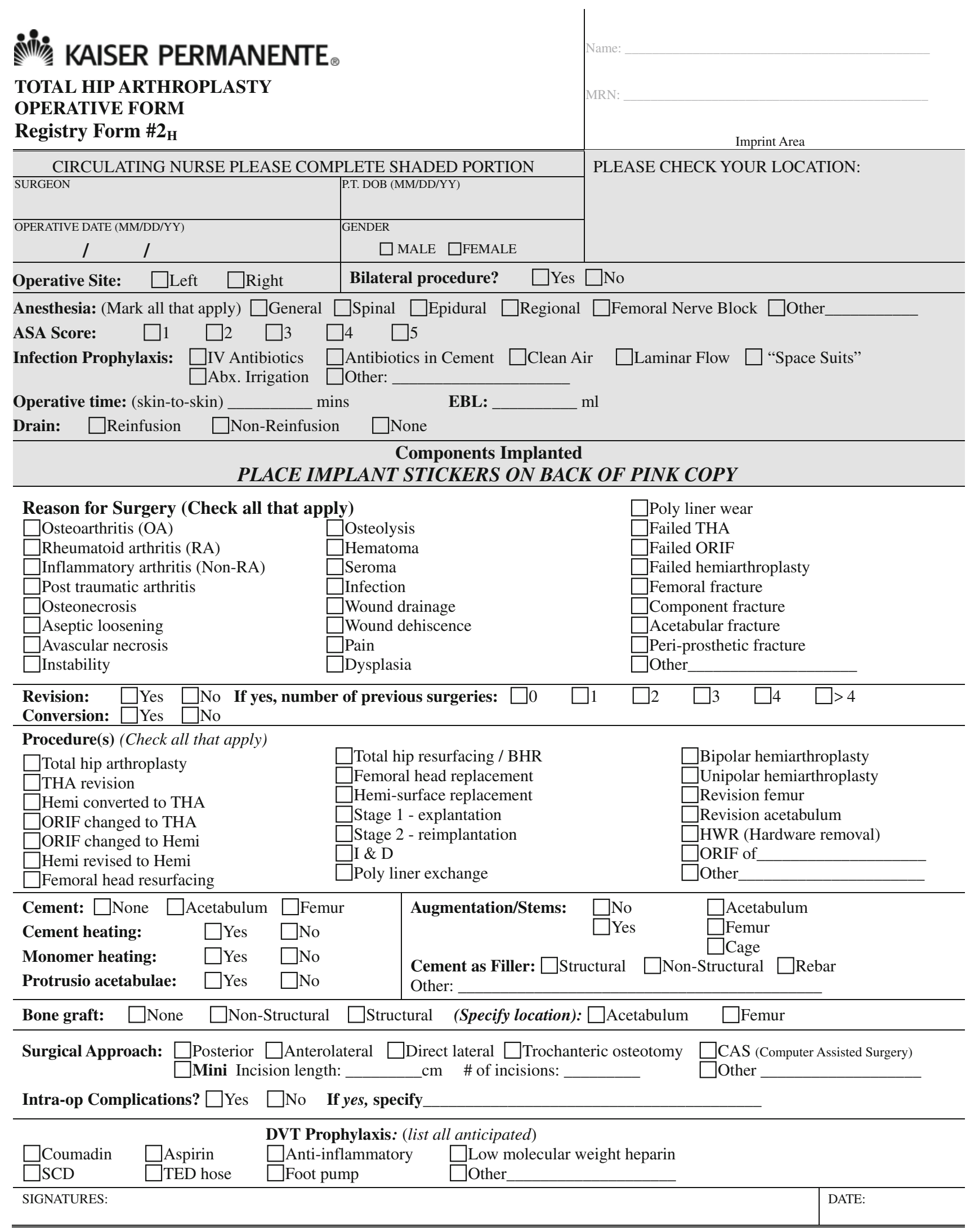




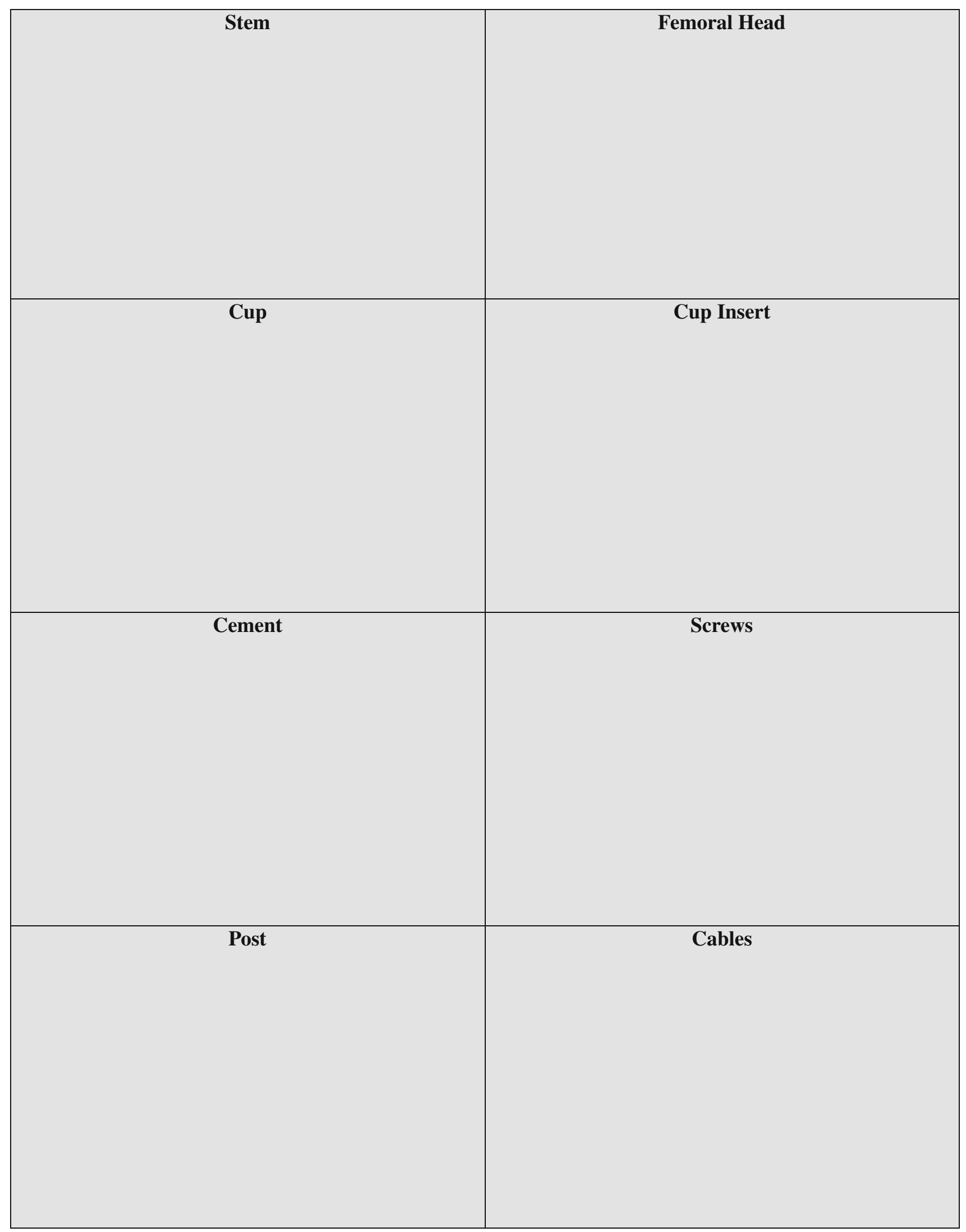




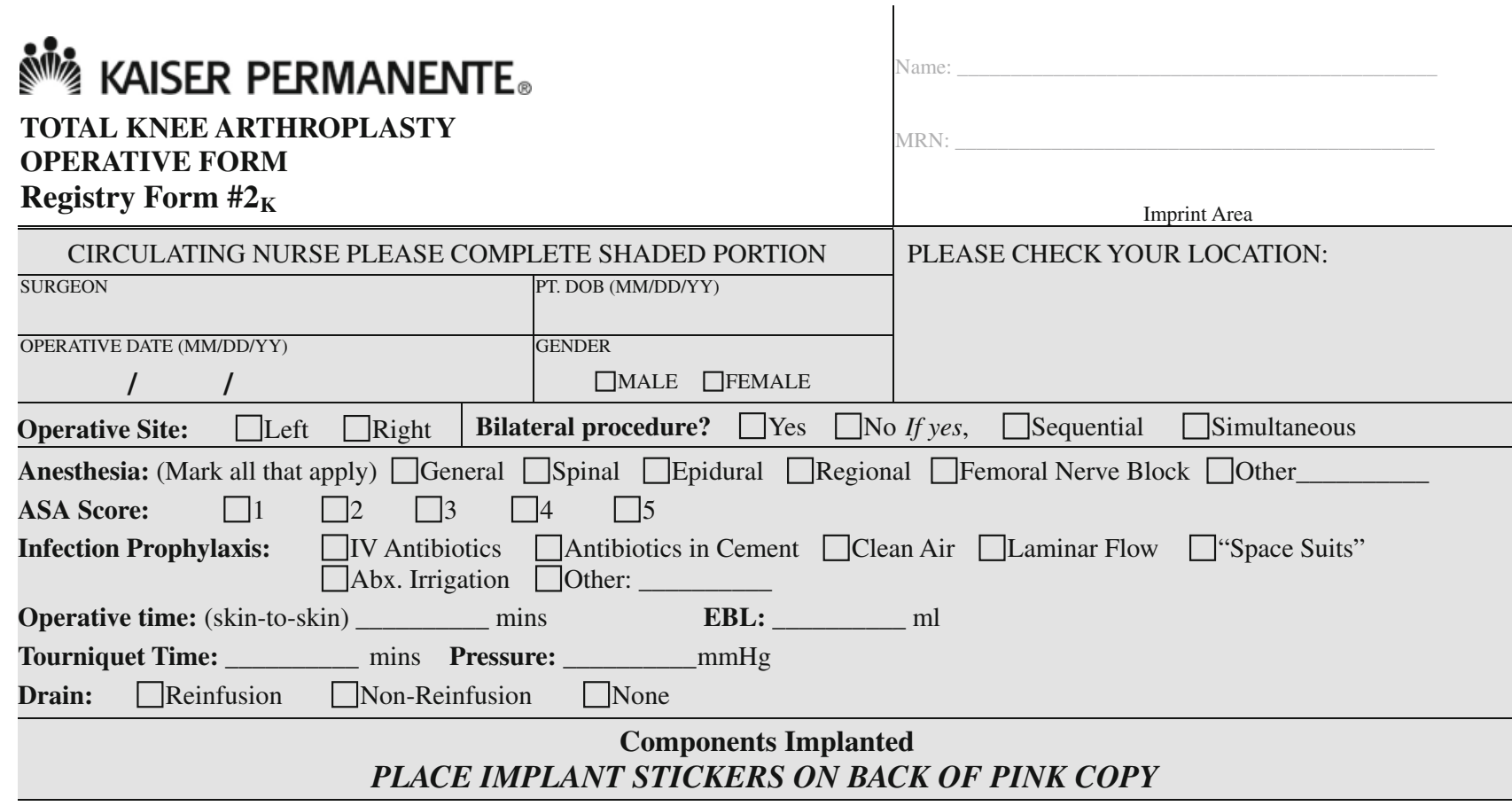

$\square$ Osteoarthritis (OA)
$\square$ Rheumatoid arthritis (RA)
$\square$ Inflammatory arthritis (Non-RA)
$\square$ Post traumatic arthritis
$\square$ Osteonecrosis
$\square$ Aseptic loosening
$\square$ Pain
$\square$ Instability
$\square$ Hematoma

\section{Reason for surgery(Check all that apply)}

$\begin{array}{ll} & \square \text { Infection } \\ & \square \text { Wound drainage } \\ \square \text { Wound dehiscence } \\ \square \text { Osteolysis } & \square \text { Poly liner wear } \\ \square \text { Arthrofibrosis } & \square \text { Femoral fracture } \\ \text { Avascular necrosis } & \square \text { Tibial fracture } \\ \square \text { Synovial impingment } & \square \text { Component fracture } \\ \text { Ingrowth failure } & \square \text { PF joint malfunction }\end{array}$

$\square$ Failed Ext. Mech. $\square$ Failed Uni-spacer $\square$ Failed HTO

$\square$ Failed ORIF

$\square$ Failed UKA

$\square$ Failed TKA

$\square$ Other:

\section{Revision: $\quad \square$ Yes $\square$ No If yes, number of previous surgeries: $\square 0 \quad \square 1 \quad \square 2 \quad \square 3 \quad \square 4 \quad \square>4$} Conversion: $\square$ Yes $\square$ No

$\square$ TKA with patella
$\square$ TKA without patella
$\square$ TKA revision
$\square$ UKA (medial or lateral)
$\square$ UKA converted to TKA
$\square$ Patellofemoral uni/arthroplasty

Procedure(s) (Check all that apply)
$\square$ ORIF changed to TKA
$\square$ Stage 1 - explantation
$\square$ Stage 2 - reimplantation
$\square$ Poly liner exchange
$\square$ I\&D

Other:

$\square$ Revision femur
$\square$ Revision tibia
$\square$ Revision patella
$\square$ ORIF of
$\square$ Synovectomy

\section{Cement: $\square$ None $\square$ Patella $\square$ Tibia $\square$ Femur $\quad$ Metal Augmentation:

Monomer heating: $\square$ Yes $\square$ No Cement heating: $\square$ Yes $\square$ No $\square$ None $\square$ Tibia $\square$ Femur

Bone graft: $\square$ None $\quad \square$ Non-Structural $\square$ Structural (Specify location): $\square$ Tibia $\square$ Femur

Soft Tissue Releases: Lateral retinaculum (patellar tracking) $\square$ Yes $\square$ No

Exposure: $\square$ Parapatellar $\square$ Mid-vastus $\square$ Sub-vastus $\square$ Tubercle osteotomy $\square$ Quadriceps release $\square$ Trivector $\square$ CAS (Computer Assisted Surgery) $\square$ Mini Incision length: __ cm $\square$ Other

Intra-op Complications? $\square$ Yes $\quad \square$ No $\quad$ If yes, specify

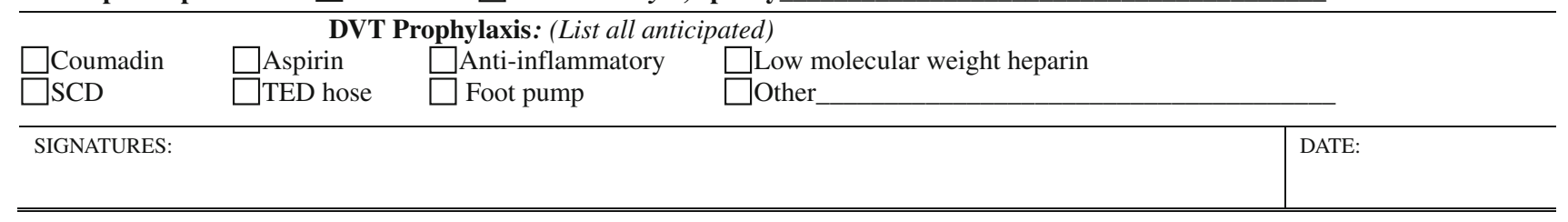




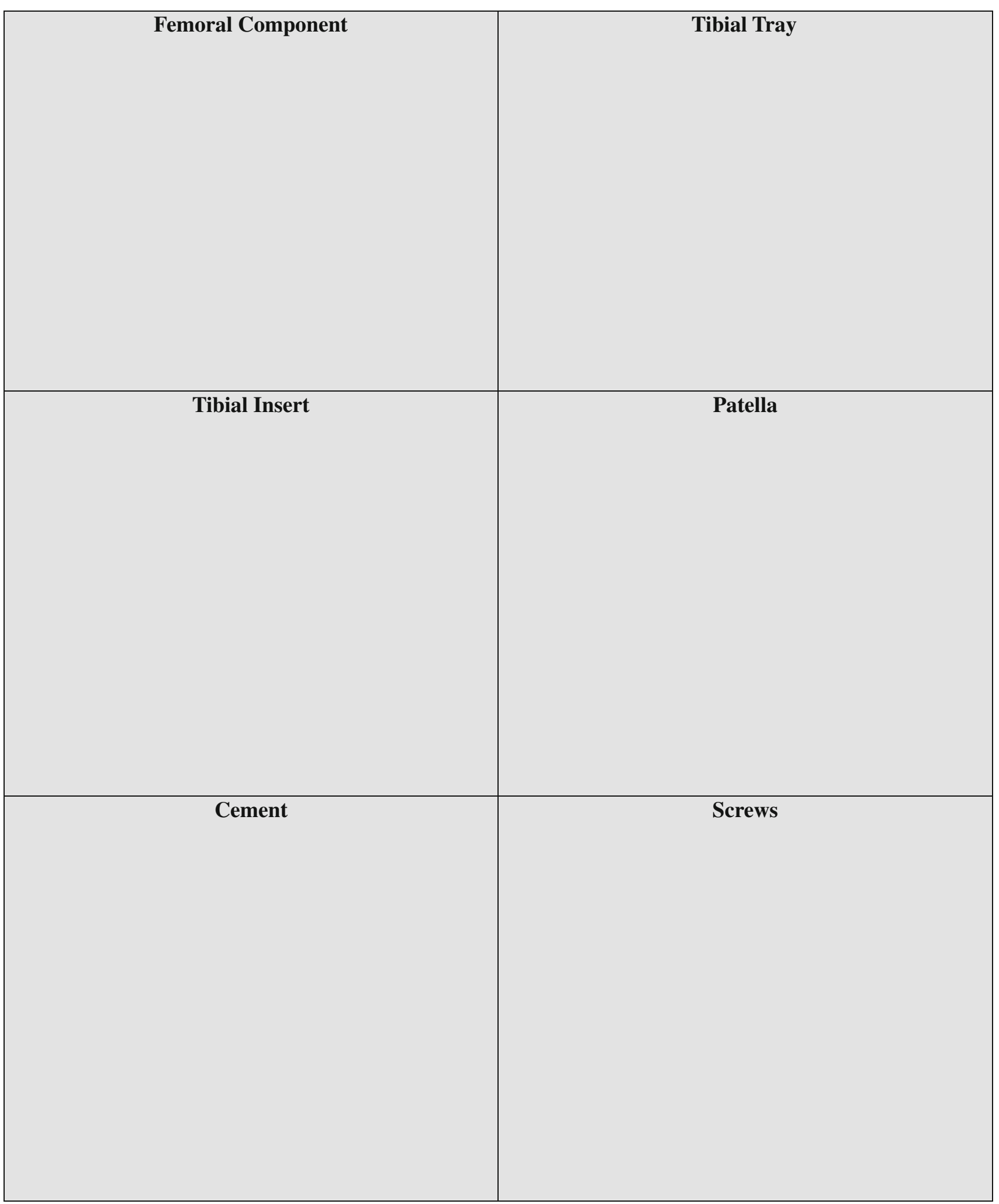


Qini KAISER PERMANENTE

\section{TOTAL JOINT ARTHROPLASTY PREOPERATIVE HISTORY AND PHYSICAL FORM Registry Form \#1A}

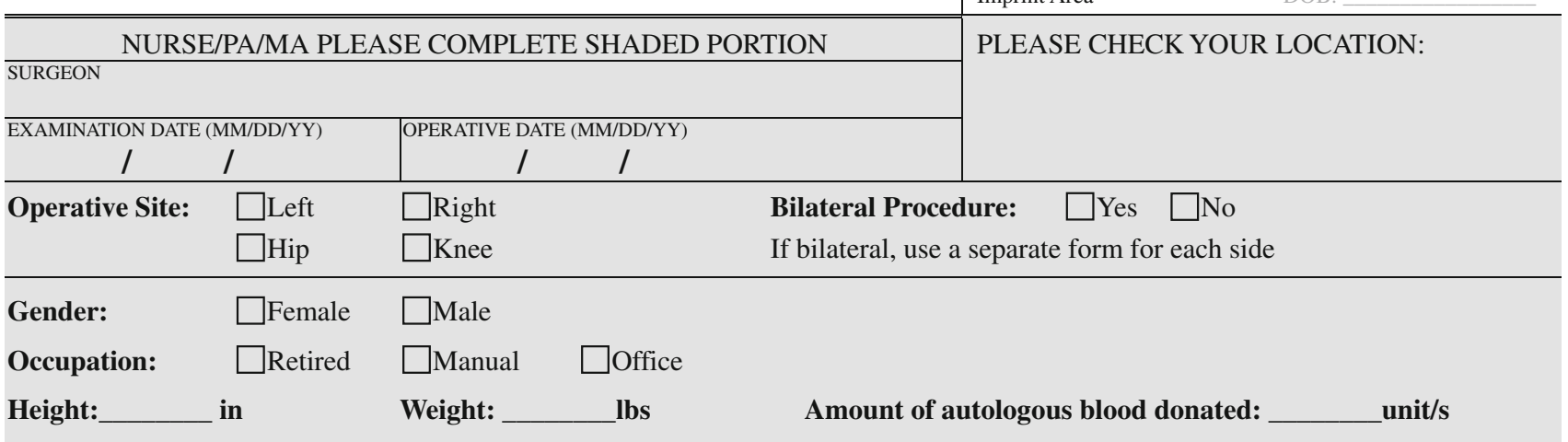

Nurse/MA Please ask the following questions:

"On a scale of 0 to 10 with $0=n o$ pain and $10=$ the worst possible pain, on average how much pain do you have in your joint being replaced?"

Other Medical Problems: (Check all that apply)

$\begin{array}{lll}\square \text { None } & \square \text { Bleeding disorder } & \square \text { Cardiac disease } \\ \square \text { Diabetes } & \square \text { Thromboembolism } & \square \text { Hypertension } \\ \square \text { Alcohol } & \square \text { Lung disease } & \square \text { Systemic steroids (current) } \\ \square \text { Smoking (current) } & \square \text { Gout } & \square \text { Other_ }\end{array}$

Ambulatory Support: $\square$ None $\square$ Yes $\square$ Wheelchair

CHARNLEY CLASSIFICATION: $\square$ A (Unilateral Joint Problem)

B (Bilateral Joint Problem)

$\square$ C (Multi-Joint Problem or Systemic Disease)

Previous Operations in this Joint:

$\square$ Hip hemiarthroplasty

$\square$ Total joint arthroplasty

\section{$\square$ None \\ Open meniscectomy \\ $\square$ Ligament reconstruction \\ $\square$ ORIF}

$\square$ Unicompartmental knee replacement $\square$ Other

\section{Number of prior surgeries in this joint: $\begin{array}{llllll}0 & \square 1 & \square 2 & \square 3 & \square 4 & \square>4\end{array}$}

Knee ROM for TKR: (Measure with goniometer)

Extension (0 degrees $=$ full $)$
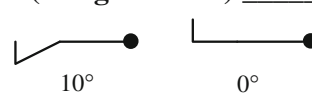

$0^{\circ}$

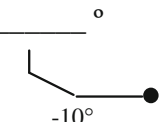

Extension Lag:

$\square$ Yes $\square$ No

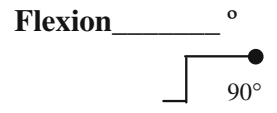

Notes: 


\section{Niํํ․ KAISER PERMANENTE \\ TOTAL JOINT ARTHROPLASTY \\ STATUS REPORT FORM \\ Registry Form \#4}

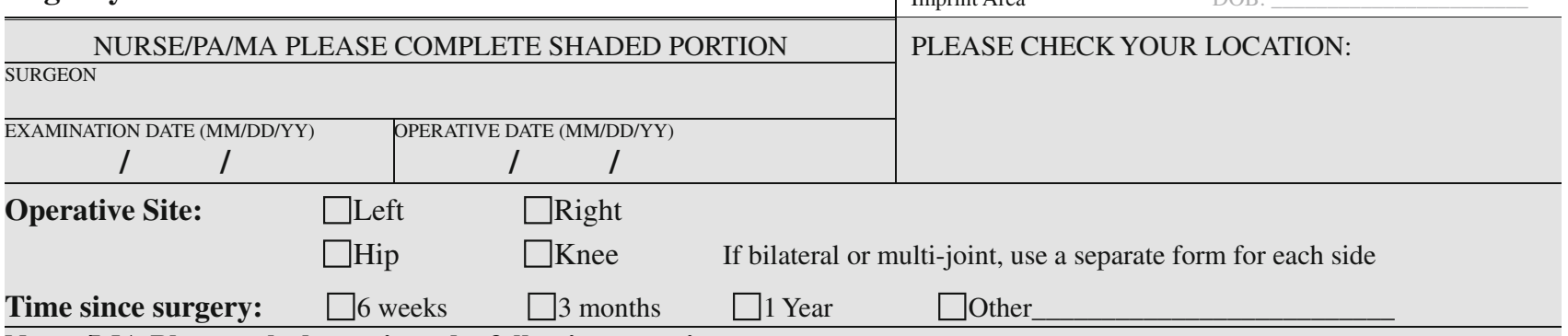

Nurse/MA Please ask the patient the following questions:

"On a scale of $\underline{0 \text { to } 10}$ with $0=$ no pain and $10=$ the worst possible pain, what is your average pain level in your joint that was replaced?"

"On a scale of $\underline{0 \text { to } 10}$ with $0=$ extremely dissatisfied and $10=$ extremely satisfied, on average how satisfied are you with the outcome of your surgery"

\begin{tabular}{|c|c|c|c|}
\hline \multicolumn{4}{|l|}{ Is a revision indicated? } \\
\hline 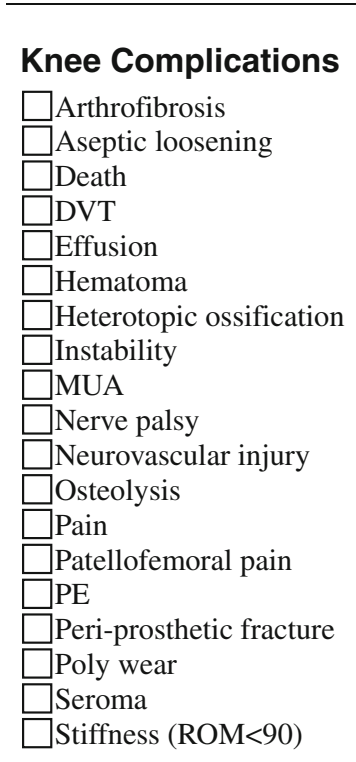 & $\begin{array}{l}\text { Other } \\
\begin{array}{l}\square \text { Leg length inequality. If } \\
\text { yes,__m }\end{array} \\
\square \text { Medical complication. If } \\
\quad \text { yes, } \\
\square \text { Other (Specify): }\end{array}$ & $\begin{array}{l}\text { Hip Complications } \\
\square \text { Arthrofibrosis } \\
\square \text { Aseptic loosening } \\
\square \text { Death } \\
\square \text { Dislocation } \\
\square \text { DVT } \\
\square \text { Effusion } \\
\square \text { Hematoma } \\
\square \text { Heterotopic ossification } \\
\square \text { Nerve palsy } \\
\square \text { Neurovascular injury } \\
\square \text { Osteolysis } \\
\square \text { Pain } \\
\square \text { PE } \\
\square \text { Peri-prosthetic fracture } \\
\square \text { Poly wear } \\
\square \text { Seroma } \\
\square \text { Thigh pain } \\
\square \text { Tronchanteric bursitis }\end{array}$ & $\begin{array}{l}\text { Radiographic } \\
\text { Assessment } \\
\text { X-Ray: } \square \text { Yes } \square \text { No } \\
\text { Loosening: } \\
\text { Acetabulum } \\
\text { Femur } \\
\text { Tibia } \\
\text { Patella } \\
\text { Osteolysis of: }\end{array}$ \\
\hline \multicolumn{4}{|c|}{$\begin{array}{ll}\text { Current Charnley Classification: } & \square \text { A (Unilateral Joint Problem) } \\
& \square \text { C (Multi-Joint Problem or Systemic Disease) } \\
\end{array}$} \\
\hline Ambulatory Support: & $\square$ None & elchair & \\
\hline \multicolumn{4}{|c|}{ Knee ROM for TKR: (Measure with goniometer) } \\
\hline$\underset{10^{\circ}}{\operatorname{Extension}\left(0^{\circ}=\mathbf{f u l l}\right)} \underbrace{}_{0^{\circ}}$ & $\begin{array}{l}\text { Hyperexte } \\
\square \text { Yes }\end{array}$ & Flexion $\underset{{\sqrt{90^{\circ}}}^{\longrightarrow}}{ }\left(\mathbf{0 - 9 0 ^ { \circ } )}\right.$ & $\begin{array}{l}\text { Extension Lag: } \\
\square \text { Yes } \square \text { No }\end{array}$ \\
\hline
\end{tabular}


Appendix 2. Total Joint Replacement Registry Smartforms examples (preoperative and postoperative)

Screen 1, Pre-operative Form, Completed by Physician's Assistant and/or Nurse

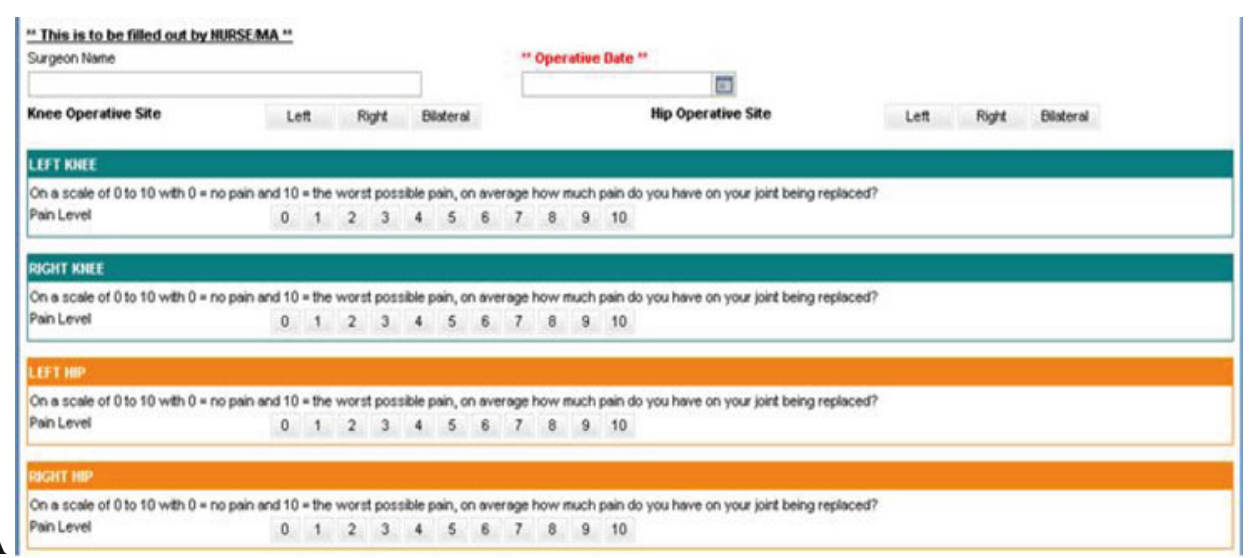

A

Screen 2, Pre-operative Form, Completed by Surgeon

Total Joint Arthroplasty Pre-Operative Form - RIGHT KNEE

\begin{tabular}{|l|l|l|l|l|l|l|l} 
Number of prior surgeries in this joint: & 0 & 1 & 2 & 3 & 4 & $>4$
\end{tabular}

Previous operations in this joint:

$\Gamma$ none

$\Gamma$ revision total knee replacement

$\Gamma$ arthroscopy

$\Gamma$ temoral revision

$\Gamma$ liganent reconstruction

$\Gamma$ tibial revision

$\Gamma$ open meniscectorny

$\Gamma$ patellar revision

Г ORIF

$\Gamma$ femoral osteotomy

$\Gamma$ total knee replacement

$\Gamma$ tibial osteotomy

$\Gamma$ unicompartmental replacement

If other selected above:

RIGHT KNEE ROM for TKR: (measure with goniometer)

Passive extension ( 0 deg $=$ full) in degrees:

Passive flexion in degrees $(0-90)$ :

B Additional notes for RIGHT KNEE: 


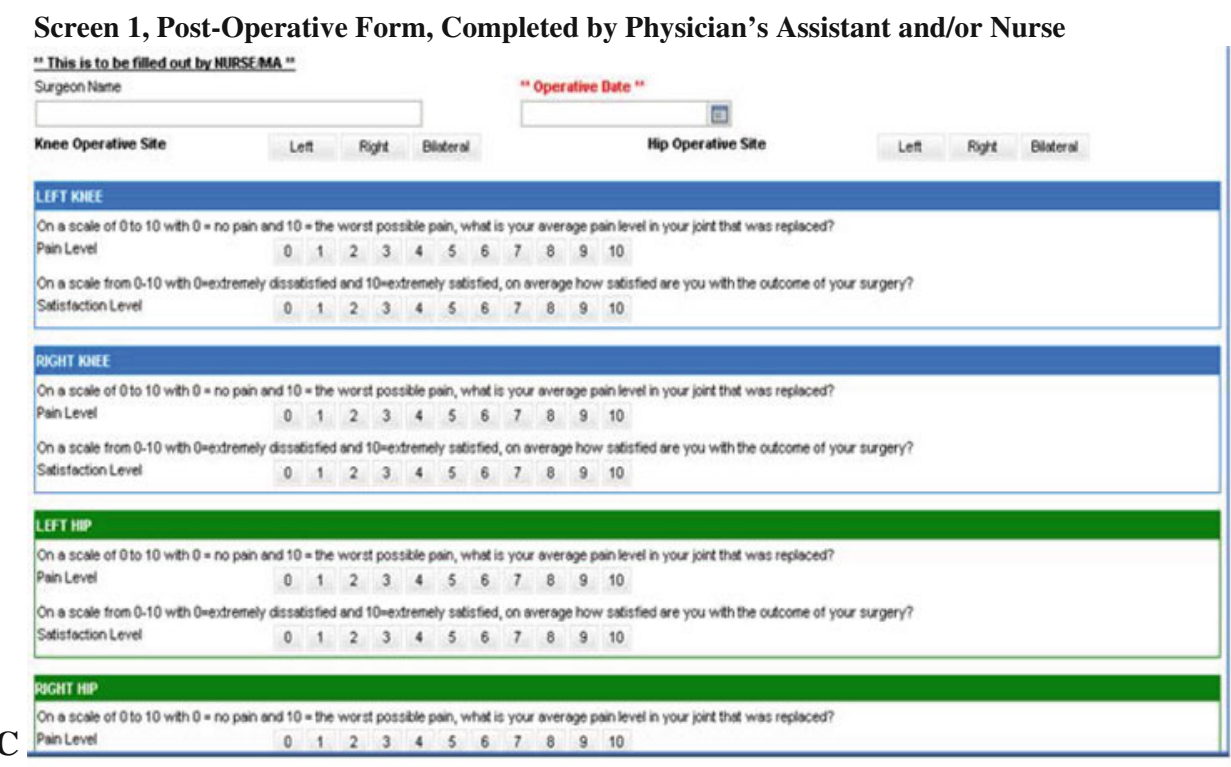

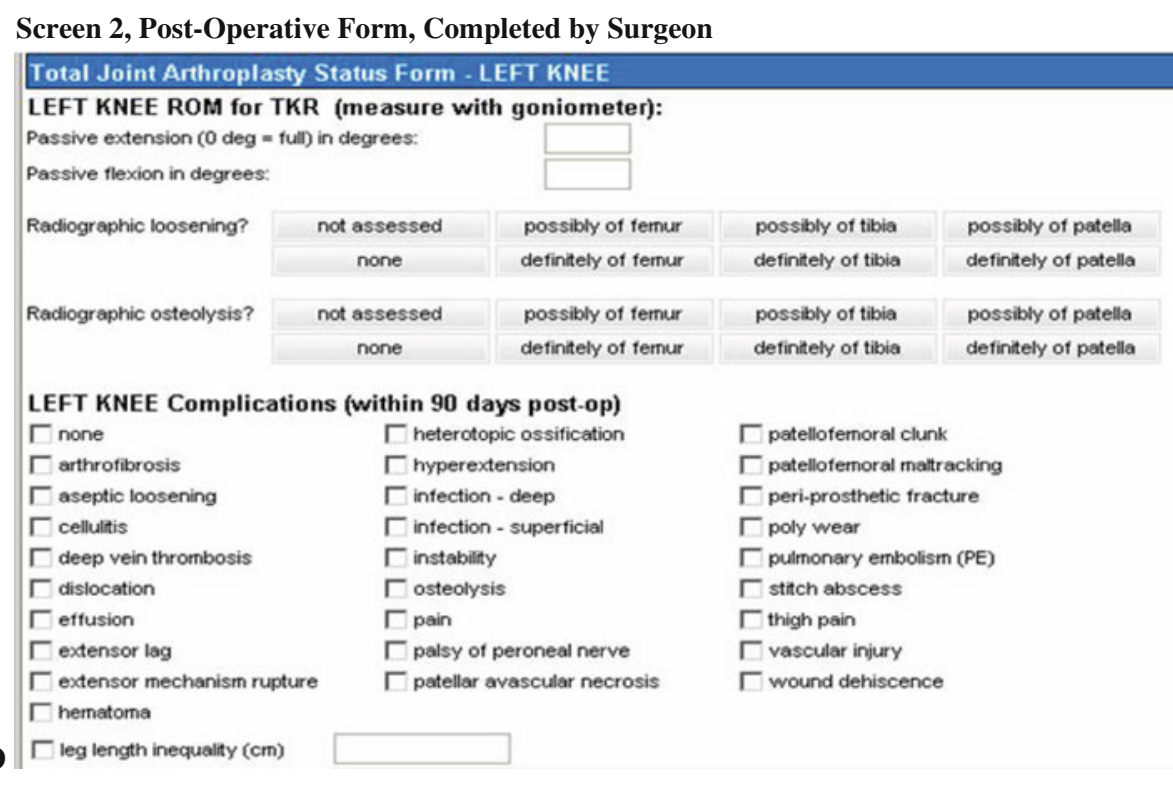

\section{References}

1. AHRQ. Agency for Healthcare Research and Quality, Quality Indicators. Patient Safety Indicators Download. Vol http://www. qualityindicators.ahrq.gov/psi_download.htm 2007. Accessed June 14, 2010.

2. American Society of Anesthesiologists. ASA Physical Status Classification System. http://www.asahq.org/clinical/physicalstatus.htm. Accessed June 14, 2010.

3. Bini SA, Fithian DC, Paxton LW, Khatod MX, Inacio MC, Namba RS. Does discharge disposition after primary total joint arthroplasty affect readmission rates? $J$ Arthroplasty. Jan 2010;25:114-117.

4. Gioe TJ, Kileen KK, Grimm K, Mehle S, Scheltema K. Why are total knee replacements revised? Clin OrthopRelat Res. 2004;428:100-110.

5. Gliklich RE, Dreyer NA. Registries for Evaluating Patient Outcomes: A User's Guide. Rockville, MD: AHRQ (Agency for
Healthcare Research and Quality); April 2007. HHSA290200500 35I T01. Publication No 07-EHC001-1.

6. Havelin LI, Engesaeter LB, Espehaug B, Furnes O, Lie SA, Vollset SE. The Norwegian Arthroplasty Register: 11 years and 73,000 arthroplasties. Acta Orthop Scand. 2000;71:337-353.

7. Herberts P, Malchau H. How outcome studies have changed total hip arthroplasty practices in Sweden. Clin Orthop Relat Res. Nov 1997;344:44-60.

8. Herberts P, Malchau H. Long-term registration has improved the quality of hip replacement: a review of the Swedish THR Register comparing 160,000 cases. Acta Orthop Scand. Apr 2000;71:111-121.

9. Khatod M, Barber T, Paxton E, Namba R, Fithian D. An analysis of the risk of hip dislocation with a contemporary total joint registry. Clin Orthop Relat Res. 2006;447:19-23.

10. Khatod M, Inacio M, Paxton EW, Bini SA, Namba RS, Burchette RJ, Fithian DC. Knee replacement: epidemiology, outcomes, and trends in Southern California: 17,080 replacements from 1995 through 2004. Acta Orthop. 2008;79:812-819. 
11. Kurtz S, Ong K, Lau E, Mowat F, Halpern M. Projections of primary and revision hip and knee arthroplasty in the United States from 2005 to 2030. J Bone Joint Surg Am. 2007;89:780-785.

12. Kurtz SM, Lau E, Ong K, Zhao K, Kelly M, Bozic KJ. Future young patient demand for primary and revision joint replacement: national projections from 2010 to 2030. Clin Orthop Relat Res. 2009;467:2606-2612.

13. Kurtz SM, Ong KL, Schmier J, Mowat F, Saleh K, Dybvik E, Karrholm J, Garellick G, Havelin LI, Furnes O, Malchau H, Lau E. Future clinical and economic impact of revision total hip and knee arthroplasty. J Bone Joint Surg Am. 2007;89 Suppl 3:144151.

14. Malchau H, Herberts $P$, Ahnfelt L. Prognosis of total hip replacement in Sweden. Follow-up of 92,675 operations performed 1978-1990. Acta Orthop Scand. 1993;64:497-506.

15. Malchau H, Herberts P, Eisler T, Garellick G, Soderman P. The Swedish Total Hip Replacement Register. J Bone Joint Surg Am. 2002;84 Suppl 2:2-20.
16. Mangram AJ, Horan TC, Pearson ML, Silver LC, Jarvis WR. Guideline for prevention of surgical site infection, 1999. Hospital Infection Control Practices Advisory Committee. Infect Control Hosp Epidemiol. 1999;20:250-278; quiz 279-280.

17. Namba RS, Chen Y, Paxton EW, Slipchenko T, Fithian DC. Outcomes of routine use of antibiotic-loaded cement in primary total knee arthroplasty. J Arthroplasty. 2009;24(6 Suppl): $44-47$.

18. Namba RS, Inacio M. Early and late manipulation improve flexion after total knee arthroplasty. J Arthroplasty. 2007;22(6 Suppl 2): $58-61$.

19. Namba RS, Paxton L, Fithian DC, Stone ML. Obesity and perioperative morbidity in total hip and total knee arthroplasty patients. J Arthroplasty. 2005;20(7 Suppl 3):46-50.

20. Paxton E, Inacio M, Slipchenko T, Fithian D. The Kaiser Permanente National Total Joint Replacement Registry. The Permanente Journal. 2008;12:12-16. Available at: www.kp.org/ permanentejournal. Accessed June 14, 2010. 